\title{
The protective role of melatonin on L-arginine-induced acute pancreatitis in adult male albino rats
}

\author{
A.S. Sadek ${ }^{1,2}$, R.T. Khattab ${ }^{1,2}$ \\ ${ }^{1}$ Department of Anatomy, Taibah University, Al-Madinah Al-Munawarah, Kingdom of Saudi Arabia \\ ${ }^{2}$ Anatomy and Embryology Department, Faculty of Medicine, Ain Shams University, Cairo, Egypt
}

[Received: 20 January 2016; Accepted: 28 April 2016]

Background: Acute pancreatitis (AP) is an inflammatory disease that has an increasing incidence worldwide. AP is associated with high morbidity and mortality rates ranging $15-40 \%$ in its severe form. Oxidative stress plays an important role in pancreatic acinar cell injury in case of AP. Melatonin (Mel) is proven to have both antioxidant and anti-inflammatory effects. The aim of the work was to investigate the protective role of Mel against L-arginine (L-arg)-induced AP in adult male albino rats. Materials and methods: Thirty-six adult male albino rats were used in this study. Animals were divided into four groups; Control group (Group $A ; n=6$ ), Mel group (Group $B ; n=6)$, L-arg group (Group $C ; n=12$ ) receiving two doses of L-arg injection with $1 \mathrm{~h}$ interval in-between, and L-arg +Mel group (Group D; $n=12$ ) receiving $M e l 1 \mathrm{~h}$ after each $L$-arg injection. $24 \mathrm{~h}$ after the second $L$-arg injection, the serum levels of amylase (AM), lipase (LP), interleukin-6 (IL-6) and tumour necrotic factor-alpha (TNF- $\alpha$ ) were determined. Then, pancreatic specimens were processed for histological and immunohistochemical staining with vascular endothelial growth factor (VEGF) and the area percentage of VEGF and collagen content were measured by digital image analysis.

Results: Microscopic examination revealed that animals received L-arg only (Group C) showed loss of the pancreatic lobular architecture with marked fibrosis, acinar degeneration, inflammatory reaction and marked oedema with vascular congestion. Also, L-arg-induced AP caused a significant elevation of the serum levels of $A M, L P, I L-6$. All these histo-pathological and serological parameters were markedly improved by Mel administration.

Conclusions: Melatonin exhibits strong therapeutic effects in the course of $A P$. Hence, the use of Mel as adjuvant treatment in AP is recommended. (Folia Morphol 2017; 76, 1: 66-73)

Key words: acinar cell, interleukin-6, vascular endothelial growth factor

\section{INTRODUCTION}

Acute pancreatitis (AP) is an inflammatory disease that has an increasing incidence worldwide. The development of systemic inflammatory response syndrome (SIRS) is one of the main causes of mortality in AP. SIRS may cause multiple organ system failure within 24-72 h [12]. Moreover, repeated attacks of AP have the potential to develop chronic pancreatitis

Address for correspondence: A.S. Sadek, MD, Anatomy Department, Faculty of Medicine, Taibah University, Al-Madinah Al-Munawarah, Kingdom of Saudi Arabia, tel: +201006049298\+966590990679, e-mail: dr_ahmedsamir79@yahoo.com 
and pancreatic cancer [36]. The experimental and clinical patho-physiology of AP is poorly understood [13]. Therefore, AP is associated with high morbidity and mortality rates ranging from $15 \%$ to $40 \%$ in its severe form [45]. L-arginine (L-arg) is an amino acid necessary for the body to make proteins. It is used to improve wound healing and decrease recovery time after surgery [5]. L-arg was previously proved by many authors to induce AP in experimental animals [21, 42].

Oxidative stress plays an important role in acinar cell injury in case of $A P$, irrespective of the initiating agent or its route of attack [11]. The release of free oxygen radicals may cause direct toxic effects on pancreatic acinar cell leading to its damage [34]. It is well known that antioxidants are potent scavengers of free oxygen radicals and serve as inhibitors of oxidative stress [1]. Melatonin (Mel), a multifunctional indolamine, is released from the pineal gland [20]. Recent studies revealed that Mel and its receptors are present in the pancreas, whereas its production is independent from the pineal gland [41]. The antioxidant activity of Mel has recently received significant attention. Mel can detoxify the hydroxyl, nitric oxide and peroxyl radicals, stimulating the activities of many scavenger enzymes including; glutathione peroxidase (GPX), superoxide dismutase (SOD) and catalase (CAT) to protect the mitochondria from oxidative injury [3]. Moreover, Mel exerts an anti-inflammatory effect by inhibiting nuclear factor kappa B (NF- $\kappa$ B) which has a major role in the development of inflammatory diseases. In turn, NF- $\kappa \mathrm{B}$ depresses the synthesis of inflammatory cytokines such as; interleukin-6 (IL-6) and tumour necrosis factor-alpha (TNF- $\alpha$ ) [15].

The aim of this study was to investigate the possible protective role of Mel against L-arg induced AP in adult male albino rats.

\section{MATERIALS AND METHODS}

\section{Experimental animals}

Thirty six adult male albino rats of the Sprague Dawley strain, 4-6 months old, with average weight 200-250 g, were used in this study. Each rat was housed in a separate stainless steel cage at room temperature $\left(20-27^{\circ} \mathrm{C}\right)$. The rats were bred and provided with food and water ad libitum. All rats were kept under the same circumstances throughout the experiment. An experiment was executed in conformity with National Institutes of Health (NIH) guidelines for the maintenance and use of science lab animals;
NIH Publication 1986 (86/609/EEC) and in accordance with local laws and ordinances.

\section{Drugs}

L-arg was purchased from El-Gomhoria Company, Egypt, in the form of powder, and dissolved in phosphate buffered saline (PBS). AP was induced by two intra-peritoneal (IP) injections of L-arg at a dose of $200 \mathrm{mg} / 100 \mathrm{~g}$ of body weight with $1 \mathrm{~h}$ interval inbetween [38].

Mel was purchased from Sigma Chemical Company, St. Louis, USA, in the form of powder, and dissolved in PBS. The dose was calculated as $50 \mathrm{mg} /$ $/ \mathrm{kg}$ of body weight, and given by IP injection $1 \mathrm{~h}$ after each L-arg injection [42].

\section{Experimental design}

Animals were divided into four groups; Control group (Group $A ; n=6$ ), Mel group (Group $B ; n=6$ ) only receiving Mel at a dose of $50 \mathrm{mg} / \mathrm{kg}$ of body weight by IP injection, L-arg group (Group $C ; n=12$ ) and L-arg+Mel group (Group D; $\mathrm{n}=12$ ). $24 \mathrm{~h}$ after the second L-arg injection, blood samples were collected from rats of all groups into sterile test tubes. The serum levels of amylase (AM), lipase (LP), IL-6 and TNF- $\alpha$ were determined. Then, all rats were sacrificed and segments from the pancreas were obtained from different groups. Specimens were formalin fixed and processed to paraffin blocks. $5 \mathrm{~mm}$-thick sections were stained with haematoxylin and eosin [18] and Masson's trichrome [7]. An immunohistochemical study was done using vascular endothelial growth factor (VEGF).

\section{Immunohistochemical staining for VEGF}

Seven-mm paraffin sections were dewaxed in $x y-$ lene and dehydrated with a graded ethanol series. Endogenous peroxidase was inactivated by incubation in $3 \%$ hydrogen peroxide. Slides were incubated overnight at $4^{\circ} \mathrm{C}$ with rabbit anti-VEGF antibody (1:500 dilutions) (Pharminagen, Mississauga, Canada). The antibody was diluted in $0.01 \mathrm{~mol} / \mathrm{L}$ PBS ( $\mathrm{pH} 7.5$ ) containing $20 \mathrm{~g} / \mathrm{L}$ bovine serum albumin and $1 \mathrm{~g} / \mathrm{L}$ sodium azide (100 L/tissue section). Goat anti-rabbit IgG (1:100 dilution) (Vector Laboratories, Burlingame, CA) was used as secondary antibody. Tissue sections were counter-stained with haematoxylin. Under the optical microscope, brown particles or patches in the cytoplasm indicated positive staining [10]. 


\section{Morphometric study}

The image analyser computer system Leica Qwin 500 (England) was used to evaluate the area percentage of VEGF and collagen content using VEGF immune-stained sections and Masson's trichromestained sections. The area percentage and standard measuring frame of a standard area equal to $118476.6 \mu \mathrm{m}^{2}$ were chosen from the parameters measuring ten readings from 5 sections from each rat from randomly chosen 5 animals of each group.

\section{Statistical analysis}

The collected data were analysed using statistical analysis system. Data were presented by mean and standard deviation. One way ANOVA was used to compare the studied four groups of rats according to the area percentage of collagen fibres, VEGF and the mean serum levels of AM, LP, IL- 6 and TNF- $\alpha$. The level of statistical significance was defined as $p \leq 0.05$ where Scheffe's multiple comparison procedure was used to indicate the significant differences among all the studied groups.

\section{RESULTS}

\section{Histological findings}

Examination of the sections of rat pancreas from the control and Mel groups (Groups A and B) looked similar, and showed normal architecture of a gland divided into lobules by connective tissue (CT) septa arise from a thin delicate CT capsule. The lobules were formed of an exocrine part with masses of endocrine part (Islets of Langerhans). The exocrine part was formed of pancreatic acini and duct system. The duct system included intra-lobular ducts within the exocrine pancreatic tissue, while the inter-lobular ducts were present in between the CT septa (Fig. 1A). Islets of Langerhans were seen in the form of pale masses, consisting of anastomosing cords of cells separated by blood capillaries (Fig. 1B). The acini appeared rounded or triangular in cross-section and they were lined by pyramidal cells with basal rounded vesicular nuclei and prominent nucleoli (Fig. 1C).

Examination of sections of the L-arg group (GroupC) showed that most of the blood vessels appeared markedly congested and dilated with extravasation of blood within the interstitial tissues. Islets of Langerhans appeared normal (Fig. 1D). There was infiltration of the pancreatic interstitium by inflammatory cells, together with marked oedema (Fig. 1E). Most of the acini appeared degenerated and showed cytoplasmic vacuolations and deeply stained pyknotic nuclei (Fig. 1F).

Examination of sections of the L-arg + Mel group (Group D) showed that the pancreatic lobular architecture appeared nearly normal. However, some acinar cells showed vacuolated cytoplasm and deeply stained pyknotic nuclei, whereas the majority of acinar cells appeared with vesicular nuclei (Fig. 1G, H).

Masson's trichrome-stained sections of the pancreas from the control and Mel groups (Groups A and $B$ ) revealed traces of collagen fibres between ducts and acini. There was marked deposition of collagen fibres between pancreatic ducts and acini in the pancreatic sections of L-arg group (Group C), while sections from L-arg+Mel group (Group D) revealed moderate deposition of collagen fibres between the pancreatic ducts and acini (Fig. 2A-C).

In the control and Mel groups (Groups A and B), no VEGF immune-staining was found in the pancreatic acinar cells, islet cells or blood vessels in the pancreas of control rats. There was positive VEGF immune-staining in the pancreatic sections of groups $C$ and D. The reaction was strong in L-arg group (Group C), especially at sites of inflammatory cellular infiltration and around blood vessels, while sections from L-arg+Mel group (Group D) showed mild VEGF immuno-staining (Fig. 3A-C).

\section{Morphometrical findings}

Statistical comparison of the area percentage of collagen fibres and VEGF expression between the different studied groups revealed that both were significantly increased in L-arg group (Group C) as compared with that of control group (Fig. 4A, B).

\section{Serological findings}

Statistical comparison of the serum levels of AM and LP between the different studied groups revealed that both were significantly increased in L-arg group (Group C) as compared with that of all other groups (Fig. 4C).

Statistical comparison of the serum levels of IL-6 and TNF- $\alpha$ between the different studied groups revealed that IL- 6 was significantly increased in L-arg group (Group C) as compared with that of all other groups. On the other hand, TNF- $\alpha$ was non-significantly increased in L-arg group (Group C) as compared with that of all other groups (Fig. 4D). 


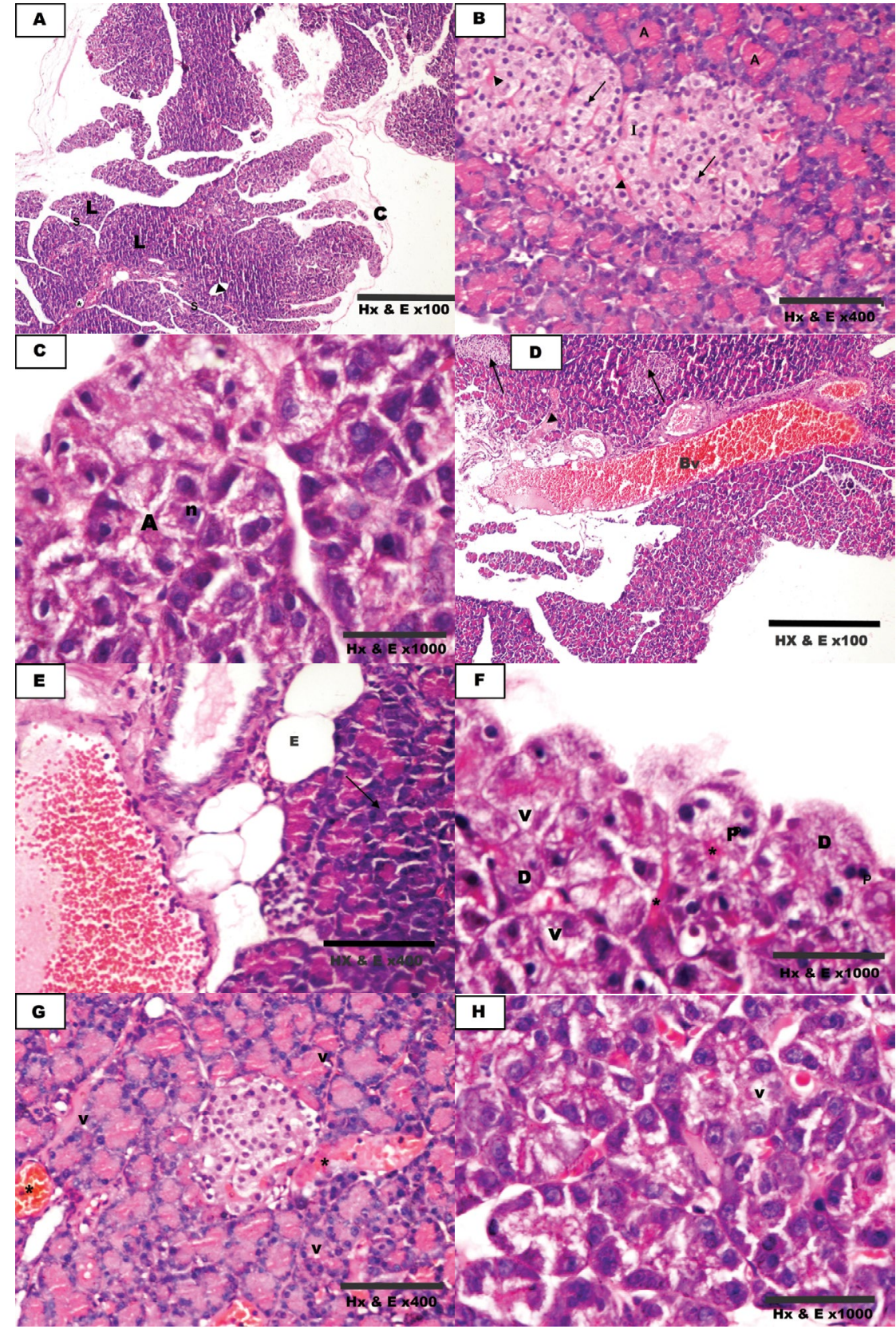

Figure 1. Photomicrographs of haematoxylin and eosin stained sections of the rat's pancreas from different groups. The control group (Group A): A. Pancreatic lobules (L) separated by connective tissue (CT) septa (S), and covered by CT capsule (C). Note the intra-lobular ducts $(\mathbf{A})$ and the inter-lobular ducts $\left({ }^{*}\right)$; B. Islets of Langerhans (I) composed of cords of endocrine cells $(\uparrow)$ separated by small blood sinusoids $(\boldsymbol{\Delta})$, and surrounded by closely packed pancreatic acini (A); C. Pancreatic acini (A) lined with large pyramidal cells with basal rounded vesicular nuclei $(\mathrm{n})$. The $\mathrm{L}$-arg group (Group C): D. Markedly congested and dilated blood vessels (Bv) with extravasation of blood $(\boldsymbol{\Delta})$ in the interstitial tissues, while Islets of Langerhans ( $\uparrow$ ) appear normal; $\mathbf{E}$. The pancreatic interstitium shows marked oedema (E) and inflammatory cellular infiltrate $(\uparrow)$; $\mathbf{F}$. The pancreatic architecture is markedly distorted showing multiple interstitial haemorrhagic areas $\left(^{*}\right)$. Most of the acini appear degenerated (D) with cytoplasmic vacuoles $(V)$ and pyknotic nuclei $(P)$. The L-arg+Mel group (Group D): G. Normal pancreatic architecture, although some acini still show minimal vacuolation (V) and focal haemorrhagic spots $\left({ }^{*}\right)$ in the pancreatic interstitium; H. Apparently normal acini appear with mild cytoplasmic vacuolation (V).

\section{DISCUSSION}

Acute pancreatitis is a localised inflammation of the pancreatic gland leads to local and systemic complications [33]. In this study, L-arg was used to induce experimental AP in rats, whereas its mechanism to induce pancreatitis is not fully clear. Biczo et al. [9] assumed that inhibition of L-arg activity ameliorates pancreatitis. L-arg is also a substrate for nitric oxide synthase (NOS) that is known to induce oxidative stress which plays an important role in the pathogenesis of AP [21]. Moreover, Lechin and Vander-Dijs [26] hypothesized that L-arg might induce AP through activation of autonomic nervous system.

Animals of the present experiment were sacrificed $24 \mathrm{~h}$ after the second L-arg injection. AP was proven to be established by this time in previous studies microscopically and also biochemically by elevation of serum AM which peaked at 12-24 $\mathrm{h}$ after L-arg injection [16, 43].

In this study, IP injection of L-arg led to loss of the pancreatic lobular architecture, marked oedema, inflammatory reaction and marked vascular congestion together with interstitial haemorrhage in the pancreatic parenchyma. These findings were in 

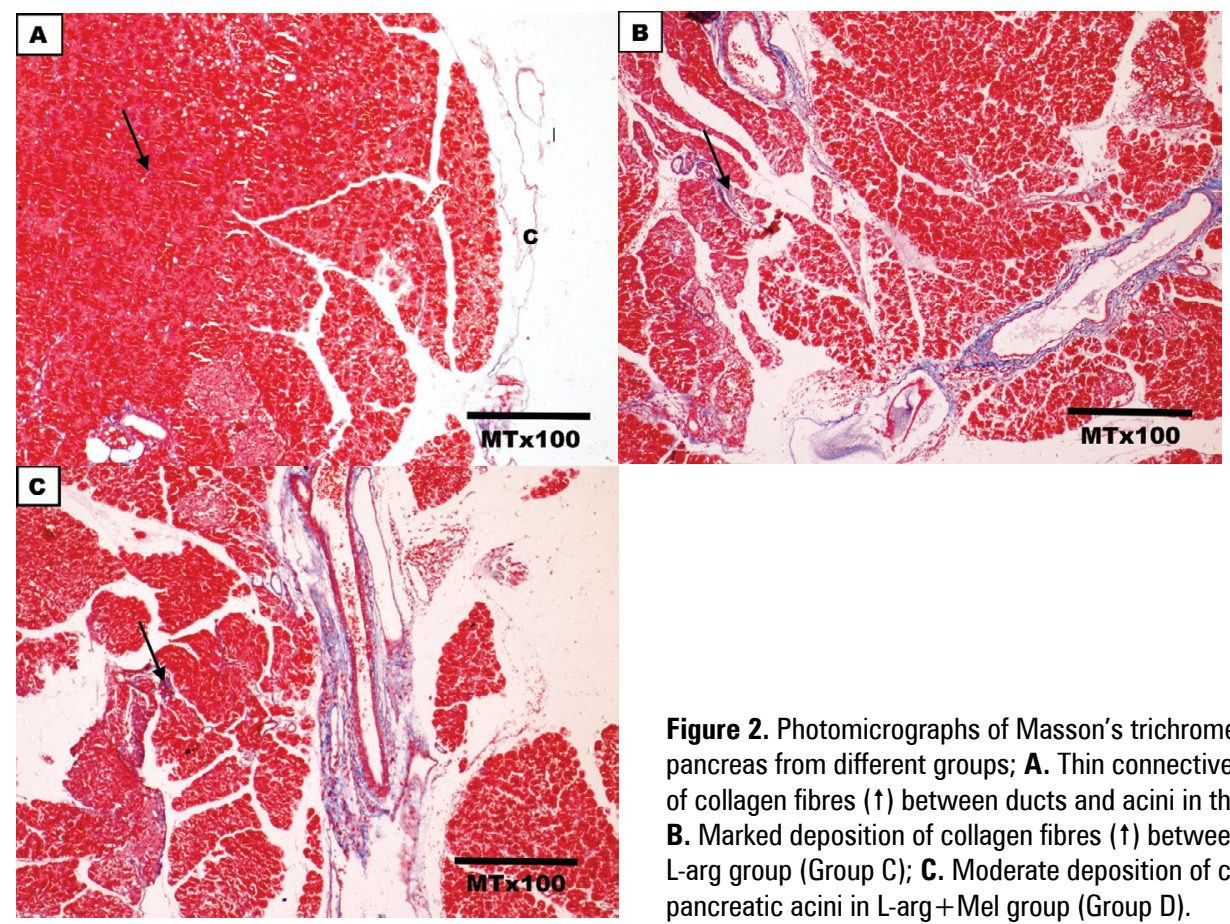

Figure 2. Photomicrographs of Masson's trichrome-stained sections of the rat's pancreas from different groups; $A$. Thin connective tissue capsule (C), with traces of collagen fibres $(\uparrow)$ between ducts and acini in the control group (Group A); B. Marked deposition of collagen fibres $(\uparrow)$ between pancreatic ducts and acini in L-arg group (Group C); C. Moderate deposition of collagen fibres in-between the pancreatic acini in L-arg+Mel group (Group D).

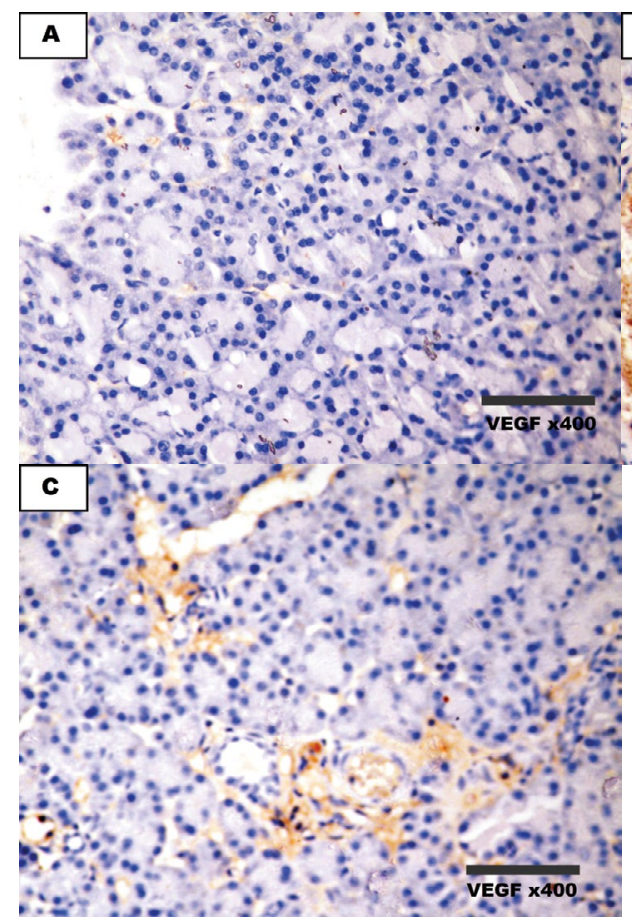

Figure 3. Photomicrographs of vascular endothelial growth factor (VEGF) immunestained sections of the rat's pancreas from different groups; $\mathbf{A}$. Control group (Group A); B. L-arg group (Group C); C. L-arg + Mel group (Group D).

agreement with the results of previous studies which reported these histo-pathological changes after 1 day of induction of AP $[19,22,44]$. According to Nevalainen and Aho [31], oedema is the most common denominator of AP induced by any method, and reflects inflammatory mechanisms. Also, Kudaril et al. [24] added that oedema is the earliest change occurred in experimentally induced AP. The vascular congestion, oedema, and extravasation of blood among pancreatic acini observed in this study could 
A
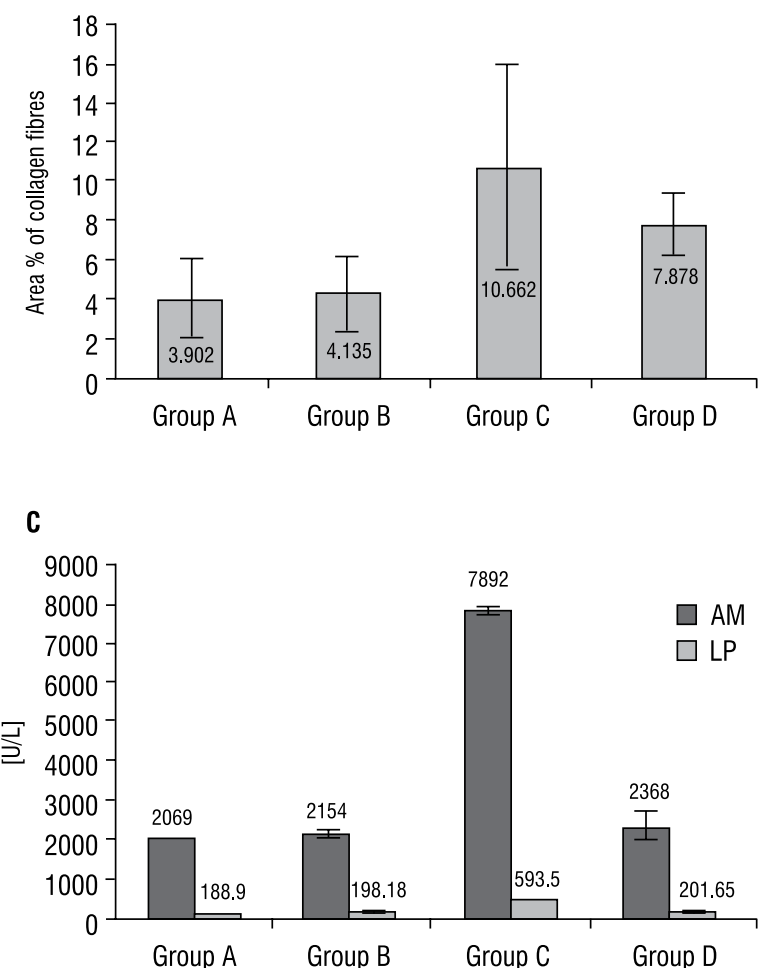

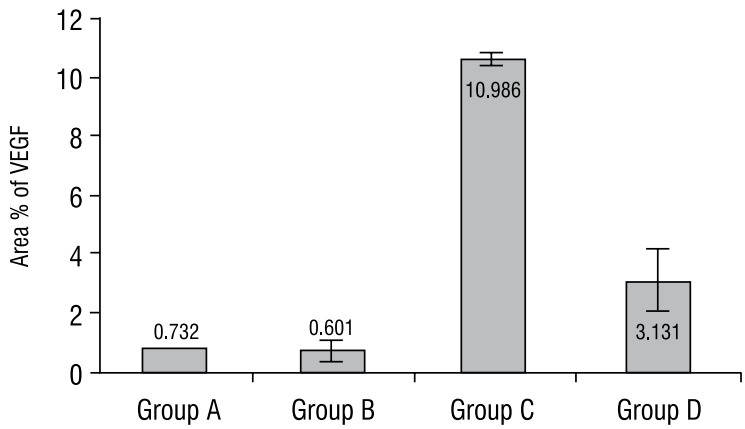

D

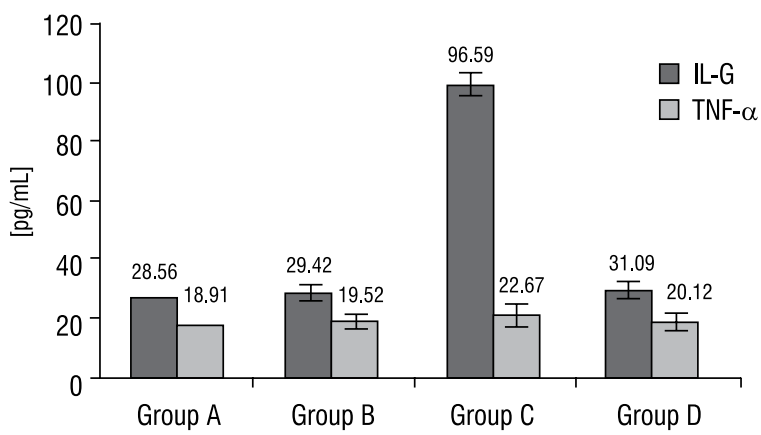

Figure 4. A. The area percentage of collagen fibres between duct and acini among the four studied groups; $\mathbf{B}$. The area percentage of vascular endothelial growth factor (VEGF) among the four studied groups; C. The serum levels of amylase (AM) and lipase (LP) among the four groups; $\mathbf{D}$. The serum levels of interleukin-6 (IL-6) and tumour necrotic factor-alpha (TNF- $\alpha$ ) among the four studied groups. Data presented as mean \pm standard deviation. $P<0.001$ is significant difference between group $C$ and other groups.

be explained by accumulation of nitric oxide (NO) produced by the activity of NOS enzyme induced by excess L-arg [37]. NO is a powerful vasodilator as it prevents the vascular smooth muscle proliferation, increasing blood flow and vascular congestion [17].

In this study, the presence of multiple cytoplasmic vacuoles in pancreatic acinar cells of the L-arg group was in agreement with Kumar et al. [25], who attributed the appearance of these vacuoles to the presence of vacuole membrane protein-1 (VMP-1) which usually appeared in the acinar cells during the early stages of AP causing cytoplasmic vacuolation followed by cell death.

In this study, despite of the marked damage observed in pancreatic acinar cells of the L-arg group, Islets of Langerhans appeared normal. This result was in agreement with many authors, who stated that L-arg could selectively induce pancreatic acinar cell damage without any morphological changes in the Islets of Langerhans $[9,16,40]$.
In this study, Masson's trichrome-stained sections of L-arg group revealed marked deposition of collagen fibres between pancreatic ducts and acini. This result was in agreement with the results of Apte and Wilson [4], who explained that the release of free radicals was associated with pancreatic fibrosis. Chen et al. [14] added that free radicals generated by xanthine oxidase could directly activate pancreatic stellate cells leading to fibrosis.

Mel was given in this study $1 \mathrm{~h}$ after each L-arg injection. Also, Szabolcs et al. [42] could detect the beneficial effect of Mel after administration of a single dose after the second injection of L-arg. On the other hand, Qi et al. [35] used repeated injections of Mel.

In this study, Mel could retain the pancreatic lobular architecture to its normal pattern. In agreement with this result, Qi et al. [35] mentioned that Mel could decrease pancreatic oedema, and mini- 
mise the extent of lipid peroxidation in the pancreas. Belyaev et al. [8] measured the morning serum Mel concentration in 75 patients with AP. They found that high endogenous Mel serum levels in the first $24 \mathrm{~h}$ after the onset of AP played a protective role in the course of the disease in humans. Moreover, pinealectomy significantly aggravated the histological manifestations of AP [23] on the other hand, Alhan et al. [2] assumed that Mel has a limited value on the course of AP as it did not alter pancreatic damage or its mortality rate in rats.

In this study, AP caused a significant elevation of the serum levels of AM, LP, IL- 6 , which could be controlled by Mel. Melo et al. [28] stated that serum AM and LP levels are important diagnostic markers for AP. They usually rise within $4-8 \mathrm{~h}$ of the initial attack, peaks at $24 \mathrm{~h}$, and returns to normal over the $72 \mathrm{~h}$. On the contrary, Alhan et al. [2] found that Mel did not change the serum activity of AM and aspartate transferase. In this study, TNF- $\alpha$ did not increase significantly during the course of AP. Accordingly, Aysel et al. [6] did not observe a significant increase in TNF- $\alpha$ in AP compared to healthy individuals.

VEGF, also known as vascular permeability factor, is secreted by different types of cells, including; smooth muscle cells, macrophages and mast cells. It is an important mediator of angiogenesis in physiological and pathological conditions [30]. Thus, VEGF might have several roles in the regeneration of the pancreas; both directly by stimulating cell maturation in the ductal epithelium, and indirectly by neoformation of capillaries [32]. In this study, there was a strong positive VEGF immune-staining at sites of inflammatory cellular infiltration and around blood vessels in the pancreatic sections of the L-arg group. It became mild in L-arg+Mel group. Accordingly, Li et al. [27] found that serum VEGF level and VEGF content within the pancreatic tissue were increased early in $A P$, and the highest level was found after $12 \mathrm{~h}$ of inducing AP. On the other hand, Nandy and Mukhopadhyay [29] mentioned that up-regulation of the VEGF/VEGF receptor system is limited to malignant transformation of the pancreas and is not associated with pancreatitis. In an attempt to explain the mechanism of Mel and VEGF interaction, Silva et al. [39] postulated that Mel may be involved in the regulation of neoangiogenesis due to its modulatory role in immunity and haematopoiesis.

\section{CONCLUSIONS}

Mel exhibits strong therapeutic effects in the course of AP. Hence, the use of Mel as adjuvant treatment in AP is recommended. However, further studies must be carried out to determine the proper dose and route of administration to achieve the best outcome for treatment.

\section{REFERENCES}

1. Akyuz C, Sehirli AO, Topaloglu U, et al. Protective Effects of Proanthocyanidin on Cerulein-induced Acute Pancreatic Inflammation in Rats. Gastroenterology Res. 2009; 2(1): 20-28, doi: 10.4021/gr2009.02.1276, indexed in Pubmed: 27956946.

2. Alhan E, Kalyoncu NI, Kural BV, et al. Effects of melatonin on acute necrotizing pancreatitis in rats. Z Gastroenterol. 2004; 42(9): 967-972, doi: 10.1055/s-2004-813321, indexed in Pubmed: 15455265.

3. Allegra M, Reiter R, Tan DX, et al. The chemistry of melatonin's interaction with reactive species. J Pineal Res. 2003; 34(1): 1-10, doi: 10.1034/j.1600-079x.2003.02112.x, indexed in Pubmed: 12485365.

4. Apte MV, Wilson JS. Mechanisms of pancreatic fibrosis. Dig Dis. 2004; 22(3): 273-279, doi: 10.1159/000082799, indexed in Pubmed: 15753610.

5. Arana V, Paz Y, González A, et al. Healing of diabetic foot ulcers in L-arginine-treated patients. Biomed Pharmacother. 2004; 58(10): 588-597, doi: 10.1016/j.biopha.2004.09.009, indexed in Pubmed: 15589068.

6. Aysel K, Mehmet I, Şeval A, et al. Serum TNF-alpha levels in acute and chronic pancreatitis. Eur J Gen Med. 2009; 6: 103-107.

7. Bancroft JB, Gamble M. Theory and practice of histological techniques, 5th Ed. Churchill Livingstone. Edinburgh, 2002.

8. Belyaev $\mathrm{O}$, Herzog T, Munding J, et al. Protective role of endogenous melatonin in the early course of human acute pancreatitis. J Pineal Res. 2011; 50(1): 71-77, doi: 10.1111/j.1600079X.2010.00811.x, indexed in Pubmed: 20964708.

9. Biczó G, Hegyi P, Berczi S, et al. Inhibition of arginase activity ameliorates L-arginine-induced acute pancreatitis in rats. Pancreas. 2010; 39(6): 868-874, doi: 10.1097/ MPA.0b013e3181d371f8, indexed in Pubmed: 20697209.

10. Boujendar S, Arany E, Hill D, et al. Taurine supplementation of a low protein diet fed to rat dams normalizes the vascularization of the fetal endocrine pancreas. J Nutr. 2003; 133(9): 2820-2825, doi: 10.1159/000243170, indexed in Pubmed: 12949371.

11. Braganza JM. Experimental acute pancreatitis. Curr Opin Gastroenterol. 1990; 6(5): 763-768, doi: 10.1097/00001574199010000-00017.

12. Bruno MJ. Current insights into the pathogenesis of acute and chronic pancreatitis. Scand J Gastroenterol Suppl. 2001(234): 103-108, doi: 10.1080/003655201753265532, indexed in Pubmed: 11768555.

13. Bülbüller N, Doğru O, Umaç H, et al. [The effects of melatonin and pentoxiphylline on L-arginine induced acute pancreatitis]. Ulus Travma Acil Cerrahi Derg. 2005; 11(2): 108-114, indexed in Pubmed: 15877240.

14. Chen X, Sans MD, Strahler JR, et al. Quantitative organellar proteomics analysis of rough endoplasmic reticulum from normal and acute pancreatitis rat pancreas. J Proteome Res. 
2010; 9(2): 885-896, doi: 10.1021/pr900784c, indexed in Pubmed: 19954227.

15. Chuang Jl, Mohan N, Meltz ML, et al. Effect of melatonin on NF-kappa-B DNA-binding activity in the rat spleen. Cell Biol Int. 1996; 20(10): 687-692, doi: 10.1006/cbir.1996.0091, indexed in Pubmed: 8969462.

16. Czako L, Takacs T, Varga IS, et al. Involvement of oxygen-free radicals in L-arginine-induced acute pancreatitis. Dig Dis and Sci, 1998; 43(8): 432-434.

17. Delaney $C P$, McGeeney KF, Dervan $P$, et al. Pancreatic atrophy: a new model using serial intra-peritoneal injections of L-arginine. Scand J Gastroenterol. 1993; 28(12): 1086-1090, doi: 10.3109/00365529309098314, indexed in Pubmed: 8303212.

18. Drury R, Wallington E. Carleton Histological techniques, 5th Ed. Oxford University Press, London, New York and Toronto, 1980.

19. Esa WI, Soliman Ms, Kefafy M, et al. Histological study on the possible protective effect of pentoxifylline on pancreatic acini of I-arginine-induced acute pancreatitis in adult male albino rats. Menoufia Med J. 2014; 27(4): 801-808, doi: 10.4103/1110-2098.149789.

20. Esteban S, Garau C, Aparicio S, et al. Chronic melatonin treatment and its precursor L-tryptophan improve the monoaminergic neurotransmission and related behavior in the aged rat brain. J Pineal Res. 2010; 48(2): 170-177, doi: 10.1111/j.1600-079X.2009.00741.x, indexed in Pubmed: 20082664

21. Hardman J, Shields C, Schofield D, et al. Intravenous antioxidant modulation of end-organ damage in L-arginineinduced experimental acute pancreatitis. Pancreatology. 2005; 5(4-5): 380-386, doi: 10.1159/000086538, indexed in Pubmed: 15980666.

22. Hegyi P, Rakonczay $Z$, Sári $R$, et al. L-arginine-induced experimental pancreatitis. World J. Gastroenterol. 2004; 10(14): 2003-2009, doi: 10.3748/wjg.v10.i14.2003, indexed in Pubmed: 15237423.

23. Jaworek J, Zwirska-Korczala K, Szklarczyk J, et al. Pinealectomy aggravates acute pancreatitis in the rat. Pharmacol Rep. 2010; 62(5): 864-873, doi: 10.1016/s1734-1140(10)70346-7, indexed in Pubmed: 21098869.

24. Kudari A, Wig JD, Vaiphei K, et al. Histopathological sequential changes in sodium taurocholate-induced acute pancreatitis. JOP. 2007; 8(5): 564-572, indexed in Pubmed: 17873460.

25. Kumar V, Abbas A, Fausto N. Robbins and Cotran pathologic basis of diseases, seventh edition. Elsevier Saunders, China, 2005; pp. 797-876.

26. Lechin F, van der Dijs B. Arginine-induced pancreatitis: involvement of the autonomic nervous system? Am J Physiol Gastrointest Liver Physiol. 2008; 294(6): G1450-G1451, doi: 10.1152/ ajpgi.00327.2007, indexed in Pubmed: 18541710.

27. Li S, Chen Xi, Wu T, et al. Role of heparin on serum VEGF levels and local VEGF contents in reducing the severity of experimental severe acute pancreatitis in rats. Scand J Gastroenterol. 2012; 47(2): 237-244, doi: 10.3109/00365521.2011.64706 3, indexed in Pubmed: 22214372.

28. Melo CM, Carvalho KM, Neves JC, et al. Alpha,beta-amyrin, a natural triterpenoid ameliorates L-arginne-induced acute pancreatitis in rats, World J Gastroenterol, 2010; 16(34): 4272-4280.

29. Nandy D, Mukhopadhyay D. Growth factor mediated signaling in pancreatic pathogenesis. Cancers (Basel). 2011; 3(1): 841-871, doi: 10.3390/cancers3010841, indexed in Pubmed: 24212642.
30. Neufeld G, Cohen T, Gengrinovitch S, Poltorak Z. Vascular endothelial growth factor (VEGF) and its receptors. FASEB J, 1999; 13: 9-22.

31. Nevalainen TJ, Aho HJ. Standards of morphological evaluation and histological grading in experimental acute pancreatitis. Eur Surg Res. 1992; 24 Suppl 1: 14-23, doi: 10.1159/000129235, indexed in Pubmed: 1601020.

32. Öberg-Welsh C, Sandler S, Andersson A, et al. Effects of vascular endothelial growth factor on pancreatic duct cell replication and the insulin production of fetal islet-like cell clusters in vitro. Mol Cell Endocrinol. 1997; 126(2): 125-132, doi: 10.1016/s0303-7207(96)03977-9.

33. Pérez $S$, Pereda J, Sabater $L$, et al. Redox signaling in acute pancreatitis. Redox Biol. 2015; 5: 1-14, doi: 10.1016/j.redox.2015.01.014, indexed in Pubmed: 25778551.

34. Pooran N, Indaram A, Singh P, et al. Cytokines (IL-6, IL-8, TNF): early and reliable predictors of severe acute pancreatitis. J Clin Gastroenterol. 2003; 37(3): 263-266, doi: 10.1097/00004836200309000-00013, indexed in Pubmed: 12960727.

35. Qi W, Tan DX, Reiter RJ, et al. Melatonin reduces lipid peroxidation and tissue edema in cerulein-induced acute pancreatitis in rats. Dig Dis Sci. 1999; 44(11): 2257-2262, indexed in Pubmed: 10573371.

36. Robbins K. Basic pathology. Elsevier publications, Chicago, USA. 2002; pp. 675.

37. Saka $M$, Tüzün $A$, Ateş $Y$, et al. Acute pancreatitis possibly due to arginine use: a case report. Turk J Gastroenterol. 2004; 15(1): 56-58, indexed in Pubmed: 15264124.

38. Sidhu S, Pandhi P, Malhotra S, et al. Melatonin treatment is beneficial in pancreatic repair process after experimental acute pancreatitis. Eur J Pharmacol. 2010; 628(1-3): 282-289, doi: 10.1016/j.ejphar.2009.11.058, indexed in Pubmed: 19958759.

39. Silva Sd, Ximenes VF, Livramento JA, et al. High concentrations of the melatonin metabolite, N1-acetyl-N2-formyl5-methoxykynuramine, in cerebrospinal fluid of patients with meningitis: a possible immunomodulatory mechanism. J Pineal Res. 2005; 39(3): 302-306, doi: 10.1111/j.1600079X.2005.00247.x, indexed in Pubmed: 16150112.

40. Smotkin J, Tenner S. Laboratory diagnostic tests in acute pancreatitis. J. Clin. Gastroenterol. 2002; 34(4): 459-462, doi: 10.1097/00004836-200204000-00018, indexed in Pubmed: 11907364.

41. Stebelová K, Herichová I, Zeman M. Diabetes induces changes in melatonin concentrations in peripheral tissues of rat. Neuro Endocrinol Lett. 2007; 28(2): 159-165, indexed in Pubmed: 17435669.

42. Szabolcs A, Reiter RJ, Letoha T, et al. Effect of melatonin on the severity of L-arginine-induced experimental acute pancreatitis in rats. World J Gastroenterol. 2006; 12(2): 251-258, doi: 10.3748/wjg.v12.i2.251, indexed in Pubmed: 16482626.

43. Takács T, Czakó L, Morschl E, et al. The role of nitric oxide in edema formation in L-arginine-induced acute pancreatitis. Pancreas. 2002; 25(3): 277-282, doi: 10.1097/00006676200210000-00010, indexed in Pubmed: 12370539.

44. Tashiro M, Schäfer $\mathrm{C}$, Yao $\mathrm{H}$, et al. Arginine induced acute pancreatitis alters the actin cytoskeleton and increases heat shock protein expression in rat pancreatic acinar cells. Gut. 2001; 49(2): 241-250, doi: 10.1136/gut.49.2.241, indexed in Pubmed: 11454802.

45. Zhang Z, Wang $Y$, Dong $M$, et al. Oxymatrine ameliorates L-arginine-induced acute pancreatitis in rats. Inflammation. 2012; 35(2): 605-613, doi: 10.1007/s10753-011-9352-2, indexed in Pubmed: 21633783. 